\title{
Tspyl2 Loss-of-Function Causes Neurodevelopmental Brain and Behavior Abnormalities in Mice
}

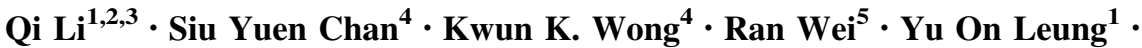 \\ Abby Y. Ding ${ }^{6}$ - Tomy C. K. Hui ${ }^{1} \cdot$ Charlton Cheung $^{1} \cdot$ Siew E. Chua ${ }^{1}$. \\ Pak C. Sham ${ }^{1,2,7} \cdot$ Ed X. Wu ${ }^{8,9} \cdot$ Grainne M. McAlonan ${ }^{10}$
}

Received: 2 July 2015/ Accepted: 9 December 2015 / Published online: 29 January 2016

(c) The Author(s) 2016. This article is published with open access at Springerlink.com

\begin{abstract}
Testis specific protein, Y-encoded-like 2 (TSPYL2) regulates the expression of genes encoding glutamate receptors. Glutamate pathology is implicated in neurodevelopmental conditions such as autism spectrum disorder, attention deficit hyperactivity disorder (ADHD) and schizophrenia. In line with this, a microduplication incorporating the TSPYL2 locus has been reported in people with ADHD. However, the role of Tspyl2 remains unclear. Therefore here we used a Tspyl2 loss-of-function mouse model to directly examine how this gene impacts upon behavior and brain anatomy. We hypothesized that Tspyl2 knockout (KO) would precipitate a phenotype relevant to neurodevelopmental conditions. In line with this prediction, we found that $T s p y l 2 \mathrm{KO}$ mice were marginally
\end{abstract}

Edited by Tamara Phillips.

Electronic supplementary material The online version of this article (doi:10.1007/s10519-015-9777-8) contains supplementary material, which is available to authorized users.

Siu Yuen Chan

sychan@hku.hk

$\bowtie$ Grainne M. McAlonan

grainne.mcalonan@kcl.ac.uk

1 Department of Psychiatry, The University of Hong Kong, Hong Kong SAR, China

2 State Key Laboratory for Cognitive and Brain Sciences, The University of Hong Kong, Hong Kong SAR, China

3 HKU-SIRI, The University of Hong Kong, Hong Kong SAR, China

4 Department of Paediatrics and Adolescent Medicine, The University of Hong Kong, Hong Kong SAR, China

5 Institute of Basic Medicine, Shandong Academy of Medical Sciences, Jinan, China more active, had significantly impaired prepulse inhibition, and were significantly more 'sensitive' to the dopamine agonist amphetamine. In addition, the lateral ventricles were significantly smaller in KO mice. These findings suggest that disrupting Tspyl2 gene expression leads to behavioral and brain morphological alterations that mirror a number of neurodevelopmental psychiatric traits.

Keywords Tspyl2 + Prepulse inhibition - Locomotion · Lateral ventricles $\cdot$ MRI

\section{Introduction}

Testis Specific Protein, Y-encoded Like 2 (TSPYL2) is $\mathrm{X}$-linked and expressed in both the developing and adult brain (Lin et al. 2006). It has been independently identified by a number of groups, and variously named: NP79 (Sun et al. 2002), CINAP (Wang et al. 2004), CDA1 (Chai et al.

6 Medical Physics and Research Department, Hong Kong Sanatorium and Hospital, The University of Hong Kong, Hong Kong SAR, China

7 Genome Research Centre, The University of Hong Kong, Hong Kong SAR, China

8 Laboratory of Biomedical Imaging and Signal Processing, The University of Hong Kong, Hong Kong SAR, China

9 Department of Electrical and Electronic Engineering, The University of Hong Kong, Hong Kong SAR, China

10 Department of Forensic and Neurodevelopmental Science, Institute of Psychiatry, Psychology and Neuroscience, King's College, London, UK 
2001), and DENTT (Ozbun et al. 2001). The gene is known to play a role in cell proliferation ( $\mathrm{Li}$ and Lau 2008), transforming growth factor beta 1 signaling pathway (Ozbun et al. 2001), and synaptic function (Wang et al. 2004; Kristiansen et al. 2010). For example, by binding Calcium/Calmodulin-dependent serine protein kinase (CASK), TSPYL2 forms a complex with the T-box transcription factor T-brain-1 (Tbr1) (Wang et al. 2004). Tbr1 drives the expression of numerous genes critical for neurodevelopment including $N$-methyl-D-aspartic acid (NMDA) receptor subunit $2 \mathrm{~b}$ (NR2B) and reelin (Wang et al. 2004). We have previously shown that Tspyl2 loss-offunction mice generated on a $129 \mathrm{~Sv} / \mathrm{Ev}$ background have reduced expression of NR2B (Tsang et al. 2014), though others have reported that this is not evident on a C57BL/6 background (Chung et al. 2011). Consistent with a possible role for Tspyl2 pathways in neurodevelopment, Xp11.2 microduplication incorporating the TSPYL2 locus has been reported in male patients with ADHD (Moey et al. 2015); human TSPYL2 is close to ALAS2, a marker linked to schizophrenia in a linkage study of 34 families (Dann et al. 1997); and mutations in CASK are linked to learning disability (Hackett et al. 2010; Tarpey et al. 2009).

Individuals with neurodevelopmental disorders have a range of behavioral abnormalities including impaired prepulse inhibition of startle (PPI) (Ornitz et al. 1992; Castellanos et al. 1996; Ornitz et al. 1999; Braff et al. 2001; McAlonan et al. 2002; Roussos et al. 2015) and differences in activity and sensitivity to amphetamine (AMPH) (Hart et al. 2014; O'Daly et al. 2011; Strakowski et al. 1997). They also have difficulties with social interaction and may have repetitive or 'obsessional' behaviours (Alessandri 1992; Lord et al. 2000; Pinkham et al. 2003; Russell et al. 2005). As glutamate pathways are thought to contribute, at least partly, to this range of behaviors (Hokyo et al. 2010; Li and Wolf 1999; Zhang et al. 2007), we directly tested the prediction that Tspyl2 loss-of-function on a $129 \mathrm{~Sv} / \mathrm{Ev}$ background would disrupt these behaviors. We also examined the impact of Tspyl2 loss-of-function on regional brain volumes.

\section{Materials and methods}

\section{Mice}

Animals from the breeding colony were acclimatized to reversed light-dark cycle (light off: 7A.M. to 7P.M.) for 4 weeks before testing. All experiments described in the present study occurred during the dark phase.

Male mice with a loss-of-function mutation of the Tspyl2 gene $\left(T s p y l 2^{m / Y}\right)$, designated knockout $(\mathrm{KO})$ and their wildtype (WT) littermates were used throughout the study. The generation of KO mice on a pure $129 \mathrm{~Sv} / \mathrm{Ev}$ genetic background has been fully described previously, with the loss of Tspyl2 transcripts (Tao et al. 2011) and protein (Tsang et al. 2014). When animals from the breeding colony became available they were entered into in vivo testing. Eight batches of mice were generated over time and at least 2 different batches per group (WT/KO) were used for most of the behavioural tests. However, only one batch of mice was available for the marble burying test and three-chamber social approach test. Behavior tests were performed as follows: PPI, WT and Tspyl2 KO: $\mathrm{N}=14$ of each genotype from four different batches of mice. Four other batches were used for the remaining tests and sub-grouped as shown in Table 1. Magnetic resonance imaging (MRI) was carried out in a total of $13 \mathrm{KO}$ mice and 12 for WT mice, 5 of these were completely naïve i.e. they had no behavioral testing before the scan; 8/7 of these mice were from batch I (please see Table 1).

\section{Behavior tests}

\section{Marble burying}

Mice were introduced to a clean, sterilized large plastic rat housing cage $(42.5 \mathrm{~cm} \mathrm{~L} \times 26.6 \mathrm{~cm} \mathrm{~W} \times 18.5 \mathrm{~cm} \mathrm{H})$ filled with bedding to a depth of $5 \mathrm{~cm}$ and topped with 20 marbles evenly spaced apart in four rows of 5 marbles for $30 \mathrm{~min}$ (Gould et al. 2011). A marble was considered to be 'buried' when it was two thirds covered by bedding. The number of marbles buried by each mouse was calculated at the end of each test. To control for odor cues, the bedding was changed and marbles were thoroughly cleaned with liquid soap and ethanol between each test.

\section{Sociability}

\section{Social approach (three-chamber apparatus)}

The social testing apparatus was a rectangular threechamber box made by the Physiology Work Shop, University of Hong Kong. Each chamber was $20 \mathrm{~cm} \mathrm{~W} \times 40.5 \mathrm{~cm} \mathrm{~L} \times 22 \mathrm{~cm} \mathrm{H}$ and dividing walls were made from clear Plexiglas with small openings (3.5 $\mathrm{cm}$ in diameter) allowing access into each chamber. The chambers of the social apparatus were cleaned and fresh bedding was added between consecutive subjects (Moy et al. 2004). The test mouse was first placed in the middle chamber and allowed to explore the three chambers for $10 \mathrm{~min}$. After habituation, an unfamiliar WT mouse (stranger 1) was introduced in a side chamber. The stranger mouse was enclosed in a cylinder $(10.5 \mathrm{~cm} \mathrm{D} \times 15 \mathrm{~cm} \mathrm{H})$ with small holes evenly spaced over the entire surface of the cylinder. An identical empty cylinder was placed in the opposite chamber. Finally, while stranger 1 remained in its 
Table 1 Batch, number and age of male mice in wildtype (WT) and $T s p y l 2^{m / Y}$ knockout (KO) mice for each test

\begin{tabular}{llrcr}
\hline Batch & Experiments & $\begin{array}{l}\text { No. of wild } \\
\text { type (WT) }\end{array}$ & $\begin{array}{l}\text { No. of Tspyl2 } \\
\text { (KO mice) }\end{array}$ & $\begin{array}{l}\text { Age (postnatal } \\
\text { days) }\end{array}$ \\
\hline $1-4$ & Prepulse inhibition & 14 & 14 & 150 \\
I & Marble burying & 8 & 8 & 158 \\
I + II & Reciprocal social interaction & 15 & 15 & $158-172$ \\
I + III & MRI & 12 & 13 & 180 \\
II & Social approach (three-chamber apparatus) & 7 & 7 & 166 \\
II + IV & Open field test and amphetamine-induced locomotor activity & 13 & 15 & 188 \\
\hline
\end{tabular}

cylinder, a new unfamiliar WT male (stranger 2) was placed in the cylinder in the opposite side chamber. All the 'strangers' used were unfamiliar, of similar age and were the same sex as the target mouse. Data collection was performed using the EthoVision XT 7.1 tracking system (Noldus Technology, The Netherlands) and the time spent in each chamber was recorded.

\section{Reciprocal social interaction (one-chamber apparatus)}

The mice tested in the 1-chamber apparatus were housed together prior to testing the social interaction of each individual animal with an unfamiliar 'stranger' WT animal of the same sex. Social interaction testing was performed in a $30 \mathrm{~cm} \mathrm{~L} \times 30 \mathrm{~cm} \mathrm{~W} \times 30 \mathrm{~cm} \mathrm{H}$ white plastic arena. Activities were video-recorded by an overhead camera for $10 \mathrm{~min}$. Time spent during the interaction (nose to nose sniffing, nose to anogenital sniffing, and following) with the stranger was recorded by a researcher who was blind to group assignment (Silverman et al. 2010).

\section{Prepulse inhibition (PPI) of the acoustic startle response}

The procedures and testing parameters for evaluation of PPI have been fully described previously (Li et al. 2009). In brief, the PPI paradigm was conducted using startle chambers for mice (San Diego Instruments, San Diego, CA, USA). In a test session, a mixture of pulse-alone (100, $110,120 \mathrm{~dB})$, prepulse-plus-pulse (3 prepulse options $\times 3$ pulse options), prepulse-alone $(71,77,83 \mathrm{~dB})$, and nostimulus (background noise, $65 \mathrm{~dB}$ ) trials were presented. Animals were acclimatized for 2 min prior to the first trail. The first 6 trials were 2 pulse-alone trials of three different pulse intensities. Then followed by 10 blocks of 16 trials in pseudorandom order, each block comprised 3 pulse-alone trials, 3 prepulse-alone trials, 9 prepulse-plus-pulse trials, and 1 no-stimulus trial, with the variable intertrial interval (ITI) of a mean of $15 \mathrm{~s}$ (10-20 s). The whole session ended with a final block of 6 pulse-alone trials as in the first block. PPI was calculated by the following formula: $100 \% \times[1-($ mean reactivity on prepulse-plus-pulse trials/mean reactivity on pulse-alone trials)].

\section{Spontaneous locomotor activity in the open field}

The apparatus comprised 4 identical cubes made of Plexiglas with a white opaque bottom, each measuring $40 \mathrm{~cm} \mathrm{~W} \times 40 \mathrm{~cm} \mathrm{~L} \times 40 \mathrm{~cm} \mathrm{H}$. In the middle of the floor a central arena $(13.5 \mathrm{~cm} \times 13.5 \mathrm{~cm})$ was demarcated by a red line (Meyer et al. 2005). Each mouse was gently placed in the centre of the appropriate arena and allowed to explore undisturbed for $30 \mathrm{~min}$ to adapt to the environment. The images were captured by an overhead camera and analyzed using Ethovision tracking system (VersionXT 7.1).

\section{Locomotor response to saline (control) and AMPH}

Immediately after the open field test, each animal was gently removed from the arena and $5 \mathrm{ml} / \mathrm{kg} 0.9 \% \mathrm{NaCl}$ was administered intraperitoneally. The mice were then returned to the arena for a further $30 \mathrm{~min}$. Afterwards, they were carefully removed and given an intraperitoneal injection of AMPH and returned for a final $60 \mathrm{~min}$. AMPH sulfate, (Sigma-Aldrich) was dissolved in $0.9 \% \mathrm{NaCl}$ solution on the day of testing to obtain $2.5 \mathrm{mg} / \mathrm{kg}$, in a volume of $5 \mathrm{ml} / \mathrm{kg}$. This low dose was selected based on evidence that it typically elicits a measureable locomotor response in mice, with minimal stereotypic or ataxic behaviors (Meyer et al. 2005; McNamara et al. 2006). Locomotor activity was evaluated after saline and AMPH injection and indexed by the distance traveled during successive 10-min bins.

\section{MRI}

In vivo MRI scanning took place at 180 day old in a $7 \mathrm{~T}$ scanner with a maximum gradient of $360 \mathrm{mT} / \mathrm{m}(70 / 16$ PharmaScan, Bruker Biospin GmbH, Germany). Animals were anesthetized during scanning with isoflurane/air mixture at $3 \%$ for induction and $1.5 \%$ for maintenance via a nose cone. A quadrature RF coil with $23 \mathrm{~mm}$ inner diameter was used. A set of scout images [T2-weighted: Effective $\quad \mathrm{TE}=38.71 \mathrm{~ms}, \quad \mathrm{TR}=4668 \mathrm{~ms}, \quad$ No of 
Average $=6$, Rare Factor $=8$, Acquisition Matrix $=$ $256 \times 256, \quad$ FOV $=25 \times 25 \mathrm{~mm}$, Slice thickness $=$ $0.25 \mathrm{~mm}$, Scan Time $=11 \mathrm{~m} 12 \mathrm{~s}$ in axial orientation were acquired in each animal. This sequence took less than one hour (Li et al. 2009).

\section{Region of interest (ROI) measurement}

Manual measurements were done using InsightITK-Snap (http://www.itksnap.org/) by a single rater, who was blind to subject group membership. Total brain volume was measured from a mask that delineates brain tissue from the skull by using semi-automatic, region growing "3D-snake" method. Lateral ventricles, cerebral cortex, hippocampus and cerebellum were delineated according to previously described boundaries and landmarks in our own and others' studies ( $\mathrm{Li}$ et al. 2009). Voxels within the ROIs were highlighted slice-by-slice with the "Paint bush" tool. Left and right sides of ROIs were labeled separately.

\section{Statistical analysis}

Marble burying behavior, and MRI were analyzed using independent samples $t$ test. Data from the three components of the social behavior test (habituation, sociability and social novelty) were analyzed by using a chamber (stranger 1 side or the opposite side) $\times 2$ genotypes (WT, KO) univariate general linear model (GLM). Where data was not normally distributed, the values were transformed or non-parametric testing was adopted. In reciprocal social interaction, Mann-Whitney non-parametric testing was applied. In PPI, percentage PPI (\% PPI) was analyzed using a $2 \times 3 \times 3$ (genotype $\times$ prepulse level $\times$ pulse level) repeated measures GLM, and reactivity to pulse-alone trials and prepulse-alone trials was analyzed using $2 \times 3$ (genotype $\times$ pulse level) and $2 \times 3$ (genotype $\times$ prepulse level) GLM, respectively. In the open field test/locomotor responses to saline and AMPH, total distances were analyzed using a (genotype $\times 10$-min bins) GLM. In addition, the number of entries in the central arena during the open field test was analyzed using Mann-Whitney non-parametric tests in the open filed test.

\section{Results}

\section{Behavioral tests}

\section{Marble burying}

Marble burying can be considered a measure of repetitive digging behavior (Thomas et al. 2009). In the marble burying test, Tspyl2 KO mice tended to bury more marbles than WT controls, although this difference did not reach statistical significance $(\mathrm{t}=-1.85 ; p=0.085)$. (Please see Supplementary Fig. 1).

\section{Social approach (three-chamber apparatus)}

There was no main effect of genotype on the time spent exploring the whole chamber; and there was no main effect of chamber side during the habituation period. When stranger 1 was introduced, there was however a main effect of chamber $[F(1,22)=71.249, p<0.01] . T$-tests confirmed that both WT and KO mice had a significant preference for the chamber containing stranger 1 rather than the empty chamber (WT, $\mathrm{t}=6.826, p<0.001$; Tspyl2 KO, $\mathrm{t}=5.248, p<0.001)$. When stranger 2 was introduced, there was no main effect of chamber, or genotype, nor any interaction between genotype $\times$ chamber sides. Both Tspyl2 KO and WT mice spent a similar time in the chamber containing stranger 1 and the chamber with stranger 2. (Please see Supplementary Fig. 2a-c).

\section{Reciprocal social interaction (one-chamber apparatus)}

Both WT and Tspyl2 KO behaved in a social manner and there was no significant group difference in time spent on
Fig. 1 PPI in WT and Tspyl2 $2^{m /}$

${ }^{Y}$ loss-of-function mice. a \% PPI at three different pulse levels $(100,110$, and $120 \mathrm{~dB})$ and three different prepulse levels $(71,77$, and $83 \mathrm{~dB})$. b. The bar plot depicts mean\% PPI across all prepulse and pulse stimuli used in two groups. All values are mean \pm SEM. $* p<0.05$
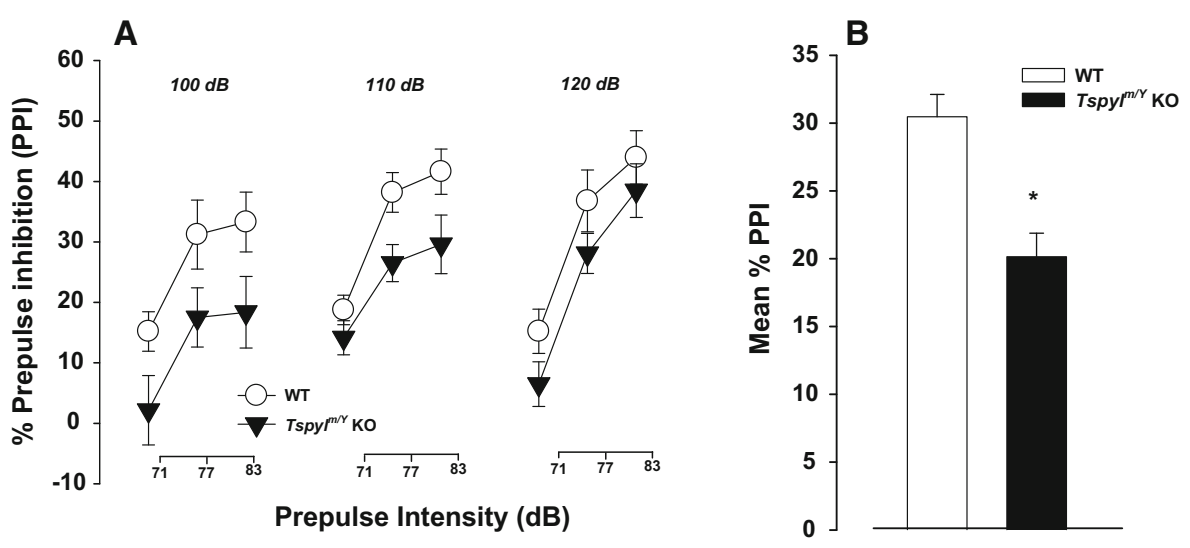


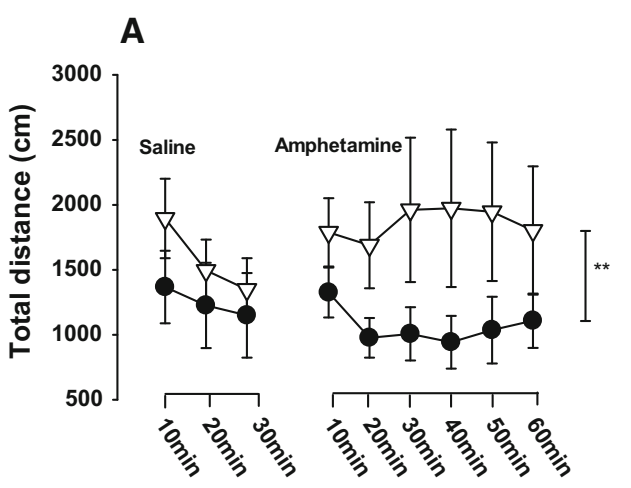

Fig. 2 Locomotor response to amphetamine challenge in the open field test. a Saline administration (30 min, left panel) and amphetamine (Amph, $2.5 \mathrm{mg} / \mathrm{kg}$ ) (60 min, right panel) challenge by timebins (10 min). b Distance travelled after Amph challenge (60 min) as a

nose-to-nose, nose-to-anogenital region sniffing and following. (Please see Supplementary Fig. 2d).

\section{$P P I$}

Sensorimotor gating was assessed using the PPI of acoustic startle reflex. Tspyl2 KO had significantly lower \% PPI compared to WT mice (Fig. 1a), main effect of genotype $[F(1,26)=5.6, p<0.05]$ (Fig. 1a, b).

There were no significant group differences in reaction to prepulse-alone trials and pulse-alone trials (Supplementary Fig. 3). Therefore, the PPI attenuating effects of Tspyl2 $\mathrm{KO}$ mice were not due to changes in general startle reactivity and/or prepulse detection, reflecting a genuine disruption of sensorimotor gating function.

\section{Spontaneous locomotor activity in the open field}

The distance moved in 10 min bins during the habituation period in the open field was taken as a measure of spontaneous locomotor activity. The Tspyl2 $\mathrm{KO}$ mice were marginally more active than WT controls, though this difference did not quite reach significance $[F(1$, $78)=4.13, p=0.054]$. Total distance travelled in $30 \mathrm{~min}$ in the open field was shown in Supplementary Fig. 4. There was no group difference in the number of entries in the central arena (Please see Supplementary Fig. 4).

\section{'Non-specific' locomotor response to saline injection}

There was no significant group difference in distance moved in $10 \mathrm{~min}$ bins following saline injection (Fig. 2a). Thus the trend towards baseline group differences in locomotion was no longer apparent.

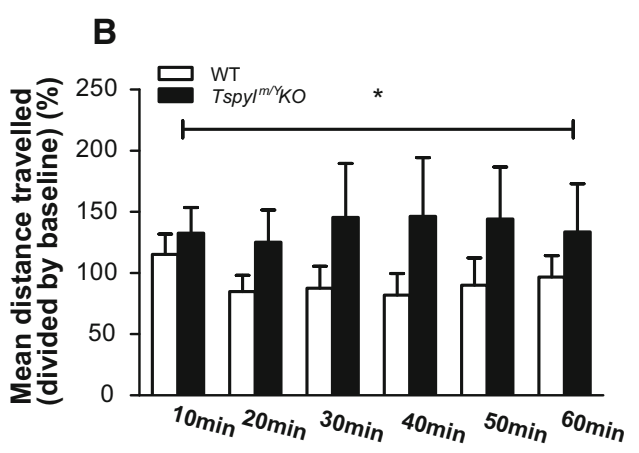

percentage of distance travelled in the final 10-min after saline injection. Tspyl2 $\mathrm{KO}$ mice had significantly greater sensitivity to Amph when compared to WT controls. All values are mean $\pm \mathrm{SEM}$. $* p<0.01 ; * * p<0.001$

\section{Locomotor response to AMPH}

Following AMPH injection, the total distance moved within the entire arena was analyzed using $2 \times 6$ (genotype $\times 10$-min bins) ANOVA. There was a significant main effect of genotype $[F(1,156)=12.464, p<0.001]$. The total distance moved was significantly greater in the Tspyl2 KO group relative to WT mice (Fig. 2a). To confirm the relative (to saline) increase in locomotion after AMPH challenge in each $\mathrm{KO}$ mice, the distance travelled in each 10 min bin following AMPH injection was divided by the distance travelled in the final $10 \mathrm{~min}$ after saline injection. This analysis confirmed that Tspyl2 $\mathrm{KO}$ mice had significantly greater sensitivity to AMPH when compared to WT controls $[\mathrm{F}(1,156)=7.034, p<0.01]$ (Fig. 2b); estimated marginal means, WT $=92.715 \pm 12.477$ (SEM) and $\mathrm{KO}=137.926 \pm 11.615(\mathrm{SEM})$.

\section{MRI}

There were no differences in regional brain volumes between the naïve mice and mice that had behavior testing in each group (data not shown). Therefore all animals with MRI data were considered together in the analyses of group differences. ROI tracing of the lateral ventricles, cerebral cortex, hippocampi and cerebellum are shown in Fig. 3a, b. Regional volumes were corrected by dividing the raw measure by the total brain volume. The total volume of the lateral ventricles (corrected) was significantly lower in Tspyl2 $\mathrm{KO}$ mice $(\mathrm{t}=2.245, p<0.05$, Fig. $3 \mathrm{c})$ as was the volume of the left and right lateral ventricle. However, there was no significant difference in the volume of the cerebral cortex, hippocampi or cerebellum (Please see Supplementary Table 1). 
Fig. 3 ROI segmentations of MRI and measurement of lateral ventricles. a Dark blue and yellow, left and right hippocampus. Red and green, left and right lateral ventricle. Pink and light blue, left and right neocortex. b Brown and purple, left and right side of cerebellum. c Ratio of total lateral ventricle/whole brain volume. $* p<0.05$. All values are mean \pm SEM

\section{A}

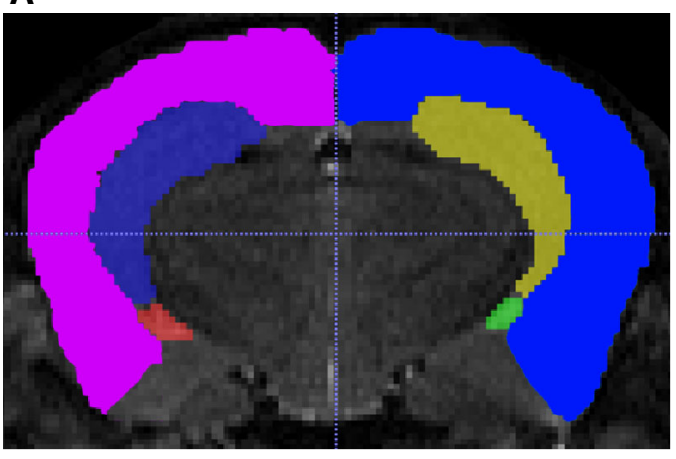

B

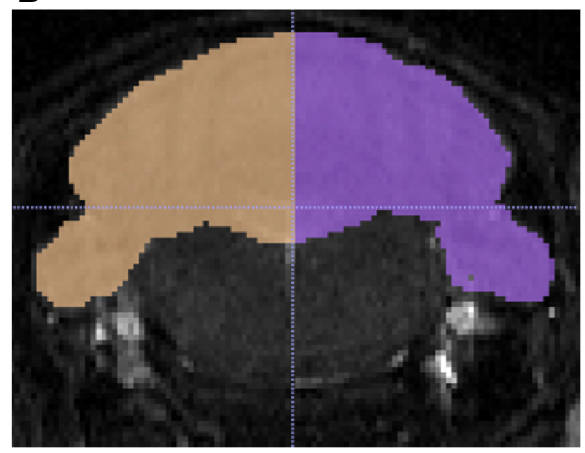

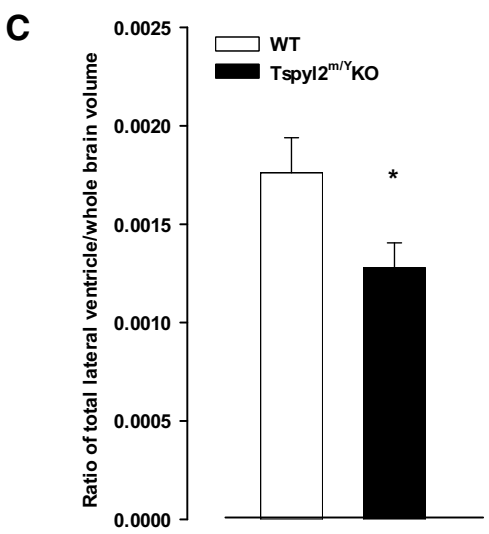

\section{Discussion}

In this study, we found that loss-of-function of the Tspyl2 gene on a $129 \mathrm{~Sv} / \mathrm{Ev}$ background led to sensorimotor gating impairment, mild hyperactivity and hyper-sensitivity to the dopamine agonist AMPH. However, Tspyl2 loss-offunction did not alter social interaction as tested here, nor did it cause gross abnormalities in volume of the whole brain, hippocampus or cerebellum, although smaller ventricular volumes were observed in $\mathrm{KO}$ mice.

\section{Behavioral effects of Tspyl2 loss-of-function}

\section{PPI}

Disruption of PPI is widely accepted as an endophenotype of schizophrenia and autism; it is also reported in individuals with ADHD complicated by comorbid enueresis (Ornitz et al. 1999). Importantly, it is one of the few paradigms in which humans and rodents are tested in similar ways (Geyer et al. 2002). PPI reflects a sensorimotor gating function which is a precognitive process to prevent sensory overload and cognitive fragmentation (Geyer et al. 2002). The findings from the experiments on humans and rodents indicate that dopaminergic manipulations modify prepulse effects on startle response (Talledo et al. 2009; Mosher et al. 2015; Depoortere et al. 1997).
However, alongside this long-standing model of dopamine dysfunction in sensorimotor gating, there is growing evidence of an interaction between dopamine and glutamate in sensorimotor gating (Wan et al. 1995), and indeed the importance of glutamate systems in the pathophysiology of schizophrenia (Coyle 2006), autism (Lee et al. 2015) and ADHD (Maltezos et al. 2014). Tspyl2 loss-of-function mice have reduced expression of NR2B (Tsang et al. 2014); and inhibition of NR2B subunit containing NMDA receptors is known to disrup t PPI (Spooren et al. 2004). Thus, PPI impairment in Tspyl2 loss-of-function mice may be a consequence of glutamate signaling disruption.

\section{Locomotor activity and response to $A M P H$}

A trend towards increased baseline locomotor activity was observed in our Tspyl2 $\mathrm{KO}$ mice. This could also be at least partly explained by glutamate dysfunction. For example, increased locomotor activity has been reported in NR2B KO animals (Badanich et al. 2011). However, NR2B loss may not be the full story as greater activity has also been reported following Tspyl2 $\mathrm{KO}$ on a different background strain that does not alter NR2B (Chung et al. 2011).

It is important to note that, although the $\mathrm{KO}$ mice were marginally more active than WT in the first $30 \mathrm{~min}$ in the open field, this activity difference had resolved prior to amphetamine challenge. Specifically, there was no 
difference in activity between WT and $\mathrm{KO}$ following a saline control injection. Thus we do not think that baseline activity differences could explain the differential response to amphetamine. Rather, glutamate dysfunction in Tspyl2 loss-of-function mice may also have contributed to their AMPH sensitivity. For example, genetic disruption of NR2B (typically lowered in these animals) can induce behavioral sensitivity to AMPH (Mao et al. 2009).

Our observation that the WT $129 \mathrm{SV} / \mathrm{Ev}$ animals had almost no response to amphetamine challenge in our study is consistent with previous reports (Chen et al. 2007; Good and Radcliffe 2011; Zhang et al. 2015). These studies agree that the 129 mouse strain has one of the lowest responses to amphetamine challenge compared to other strains. As we elected to use a particularly low dose of AMPH challenge $(2.5 \mathrm{mg} / \mathrm{kg})$ to avoid the potential confounds of stereotypy, the lack of response to AMPH in WT animals is therefore not surprising.

\section{Social function}

Our Tspyl2 KO mice had preserved social functioning, at least in the tests employed in this study. However, assessment of ecologically valid social behavior in the mouse is challenging, as is their translation to the human condition.

\section{Anatomical effects of Tspyl2 loss-of-function}

Tspyl2 loss-of-function did not have gross effects on brain anatomy. The main finding was smaller ventricular volumes in the loss-of-function animals relative to WT controls; the volumes of cortex, hippocampus and cerebellum volumes were unaltered. Across neurodevelopmental conditions, findings of enlarged ventricles in schizophrenia are reasonably robust (Jaaro-Peled et al. 2010) and animal models have been shown to replicate this feature ( $\mathrm{Li}$ et al. 2009; Piontkewitz et al. 2011). Also, posterior lateral ventricular enlargement has been reported in ADHD (Lyoo et al. 1996). However, MRI findings in studies of autism are at variance. Young children with autism have enlarged brains which may result from both greater brain tissue volume and greater lateral ventricle volume (Piven et al. 1995). Yet, by the age of 10 years, more recent three-dimensional measurements have found smaller left frontal and occipital ventricular horns in individuals with autism spectrum disorders (Vidal et al. 2008). Preclinically, BTBR mice, an animal model with utility in autism research (McFarlane et al. 2008), has been reported to have smaller lateral ventricles compared to $\mathrm{C} 57 \mathrm{BL} / 6 \mathrm{~J}$ mice (Meyza et al. 2012). Thus, we cautiously suggest some overlap in anatomical pattern observed in our study with some reports in the autism literature.

\section{Limitations}

In this study we attempted to examine the effect of Tspyl2 gene $\mathrm{KO}$ on a range of behaviors as well as brain anatomy. This was logistically difficult and meant that not every animal in the study was tested in every paradigm. This may have been a particular issue for the marble burying task as the small sample size possibly leads to poor statistical power and the risk of a false negative result. In addition, although the genotype of Tspyl2 KO mice was confirmed by western blot at the outset of our programme of study (Tsang et al. 2014), we did not repeat the western blot for every litter used in the present study.

\section{Conclusion}

In summary, this study demonstrates that Tspyl2 KO mice have behavioral and brain anatomical differences that model some features found in neurodevelopmental psychiatric disorders. We have previously shown that this gene regulates NMDA receptor $2 \mathrm{~A}$ and $2 \mathrm{~B}$ expression (Tsang et al. 2014). Therefore we suggest that disruption of glutamate signaling may at least partly explain the phenotype observed here, in line with evidence for a critical role of this system in neurodevelopmental psychiatric disorders.

Acknowledgments We thank Mr. Yeung and Mr. Leung from the workshop at the Department of Physiology, HKU, for their contribution to setting up this study. We also thank Prof. John A. Rudd, from School of Biomedical Sciences, The Chinese University of Hong Kong, who provided reagents used in this study. We are grateful to Dr. KS Lo and all his staff at LAU extension, HKU, whose contributions were crucial to the smooth running of this project. This study was funded in part by a GRF (774710) award to Dr. McAlonan, a University of Hong Kong award (201309176074) and NSFC-Young Investigator (81300987) to Dr. Li Qi and donation to 'Development and Disease' programme and funding from HKU to Dr. SY Chan. Dr McAlonan is a member of the EU-AIMS consortium. The funders had no role in the design of the study or decision to publish.

Author Contributions Conceived and designed the experiments: Grainne McAlonan, Li Qi, SY Chan. Performed the experiments: Li Qi, KK Wong, YO Leung, AY Ding, CK Hui. Data Analysis: LiQi, Wei Ran, Charlton Cheung. Wrote the paper: Li Qi, Grainne McAlaonan, SY Chan, SE Chua, EX Wu, PC Sham. All authors reviewed the manuscript for intellectual content and approved submission.

\section{Compliance with Ethical Standards}

Conflict of Interest The authors declare that they have no conflict of interests.

Ethical Approval All applicable international and institutional guidelines for the care and use of laboratory animals were followed. The Committee on the Use of Live Animals in Teaching and Research at the University of Hong Kong approved the experiments (CULATR Number: 2321-11; 2612-11). 
Open Access This article is distributed under the terms of the Creative Commons Attribution 4.0 International License (http://crea tivecommons.org/licenses/by/4.0/), which permits unrestricted use, distribution, and reproduction in any medium, provided you give appropriate credit to the original author(s) and the source, provide a link to the Creative Commons license, and indicate if changes were made.

\section{References}

Alessandri SM (1992) Attention, play, and social behavior in ADHD preschoolers. J Abnorm Child Psychol 20(3):289-302

Badanich KA, Doremus-Fitzwater TL, Mulholland PJ, Randall PK, Delpire E, Becker HC (2011) NR2B-deficient mice are more sensitive to the locomotor stimulant and depressant effects of ethanol. Genes Brain Behav 10(7):805-816

Braff DL, Geyer MA, Light GA, Sprock J, Perry W, Cadenhead KS, Swerdlow NR (2001) Impact of prepulse characteristics on the detection of sensorimotor gating deficits in schizophrenia. Schizophr Res 49(1-2):171-178

Castellanos FX, Fine EJ, Kaysen D, Marsh WL, Rapoport JL, Hallett M (1996) Sensorimotor gating in boys with Tourette's syndrome and ADHD: preliminary results. Biol Psychiatry 39(1):33-41

Chai Z, Sarcevic B, Mawson A, Toh BH (2001) SET-related cell division autoantigen-1 (CDA1) arrests cell growth. J Biol Chem 276(36):33665-33674

Chen R, Zhang MJ, Park S, Gnegy ME (2007) C57BL/6 J mice show greater amphetamine-induced locomotor activation and dopamine efflux in the striatum than 129S2/SvHsd mice. Pharmacol Biochem Behav 87(1):158-163

Chung WC, Huang TN, Hsueh YP (2011) Targeted deletion of CASKinteracting nucleosome assembly protein causes higher locomotor and exploratory activities. Neurosignals 19(3):128-141

Coyle JT (2006) Glutamate and schizophrenia: beyond the dopamine hypothesis. Cell Mol Neurobiol 26(4-6):365-384

Dann J, DeLisi LE, Devoto M, Laval S, Nancarrow DJ, Shields G, Smith A, Loftus J, Peterson P, Vita A, Comazzi M, Invernizzi G, Levinson DF, Wildenauer D, Mowry BJ, Collier D, Powell J, Crowe RR, Andreasen NC, Silverman JM, Mohs RC, Murray RM, Walters MK, Lennon DP, Crow TJ et al (1997) A linkage study of schizophrenia to markers within Xp11 near the MAOB gene. Psychiatry Res 70(3):131-143

DeLorey TM, Sahbaie P, Hashemi E, Li WW, Salehi A, Clark DJ (2011) Somatosensory and sensorimotor consequences associated with the heterozygous disruption of the autism candidate gene, Gabrb3. Behav Brain Res 216(1):36-45

Depoortere R, Perrault G, Sanger DJ (1997) Potentiation of prepulse inhibition of the startle reflex in rats: pharmacological evaluation of the procedure as a model for detecting antipsychotic activity. Psychopharmacology 132(4):366-374

Geyer MA, McIlwain KL, Paylor R (2002) Mouse genetic models for prepulse inhibition: an early review. Molecular psychiatry 7(10):1039-1053

Good RL, Radcliffe RA (2011) Methamphetamine-induced locomotor changes are dependent on age, dose and genotype. Pharmacol Biochem Behav 98(1):101-111

Gould GG, Hensler JG, Burke TF, Benno RH, Onaivi ES, Daws LC (2011) Density and function of central serotonin (5-HT) transporters, 5-HT1A and 5-HT2A receptors, and effects of their targeting on BTBR $\mathrm{T}+\mathrm{tf} / \mathrm{J}$ mouse social behavior. J Neurochem 116(2):291-303

Hackett A, Tarpey PS, Licata A, Cox J, Whibley A, Boyle J, Rogers C, Grigg J, Partington M, Stevenson RE, Tolmie J, Yates JR,
Turner G, Wilson M, Futreal AP, Corbett M, Shaw M, Gecz J, Raymond FL, Stratton MR, Schwartz CE, Abidi FE (2010) CASK mutations are frequent in males and cause $\mathrm{X}$-linked nystagmus and variable XLMR phenotypes. Eur J Hum Genet 18(5):544-552

Hart AB, Gamazon ER, Engelhardt BE, Sklar P, Kahler AK, Hultman CM, Sullivan PF, Neale BM, Faraone SV, de Wit H, Cox NJ, Palmer AA, Psychiatric Genomics Consortium AS (2014) Genetic variation associated with euphorigenic effects of d-amphetamine is associated with diminished risk for schizophrenia and attention deficit hyperactivity disorder. Proc Natl Acad Sci USA 111(16):5968-5973

Hokyo A, Kanazawa T, Uenishi H, Tsutsumi A, Kawashige S, Kikuyama H, Glatt SJ, Koh J, Nishimoto Y, Matsumura H, Motomura N, Yoneda H (2010) Habituation in prepulse inhibition is affected by a polymorphism on the NMDA receptor $2 \mathrm{~B}$ subunit gene (GRIN2B). Psychiatr Genet 20(5):191-198

Jaaro-Peled H, Ayhan Y, Pletnikov MV, Sawa A (2010) Review of pathological hallmarks of schizophrenia: comparison of genetic models with patients and nongenetic models. Schizophr Bull 36(2):301-313

Kristiansen LV, Patel SA, Haroutunian V, Meador-Woodruff JH (2010) Expression of the NR2B-NMDA receptor subunit and its Tbr-1/CINAP regulatory proteins in postmortem brain suggest altered receptor processing in schizophrenia. Synapse 64(7):495-502

Lee EJ, Choi SY, Kim E (2015) NMDA receptor dysfunction in autism spectrum disorders. In: Current opinion in pharmacology, pp 208-213

Li Y, Lau YF (2008) TSPY and its X-encoded homologue interact with cyclin B but exert contrasting functions on cyclin-dependent kinase 1 activities. Oncogene 27(47):6141-6150

Li Y, Wolf ME (1999) Can the "state-dependency" hypothesis explain prevention of amphetamine sensitization in rats by NMDA receptor antagonists? Psychopharmacology 141(4):351361

Li Q, Cheung C, Wei R, Hui ES, Feldon J, Meyer U, Chung S, Chua SE, Sham PC, Wu EX, McAlonan GM (2009) Prenatal immune challenge is an environmental risk factor for brain and behavior change relevant to schizophrenia: evidence from MRI in a mouse model. PLoS One 4(7):e6354

Lin CW, Huang TN, Wang GS, Kuo TY, Yen TY, Hsueh YP (2006) Neural activity- and development-dependent expression and distribution of CASK interacting nucleosome assembly protein in mouse brain. J Comp Neurol 494(4):606-619

Lord C, Cook EH, Leventhal BL, Amaral DG (2000) Autism spectrum disorders. Neuron 28(2):355-363

Lyoo IK, Noam GG, Lee CK, Lee HK, Kennedy BP, Renshaw PF (1996) The corpus callosum and lateral ventricles in children with attention-deficit hyperactivity disorder: a brain magnetic resonance imaging study. Biol Psychiatry 40(10):1060-1063

Maltezos S, Horder J, Coghlan S, Skirrow C, O'Gorman R, Lavender TJ, Mendez MA, Mehta M, Daly E, Xenitidis K, Paliokosta E, Spain D, Pitts M, Asherson P, Lythgoe DJ, Barker GJ, Murphy DG (2014) Glutamate/glutamine and neuronal integrity in adults with ADHD: a proton MRS study. Transl Psychiatry 4:e373

Mao LM, Wang W, Chu XP, Zhang GC, Liu XY, Yang YJ, Haines M, Papasian CJ, Fibuch EE, Buch S, Chen JG, Wang JQ (2009) Stability of surface NMDA receptors controls synaptic and behavioral adaptations to amphetamine. Nat Neurosci 12(5): 602-610

McAlonan GM, Daly E, Kumari V, Critchley HD, van Amelsvoort T, Suckling J, Simmons A, Sigmundsson T, Greenwood K, Russell A, Schmitz N, Happe F, Howlin P, Murphy DG (2002) Brain anatomy and sensorimotor gating in Asperger's syndrome. Brain 125(Pt 7):1594-1606 
McFarlane HG, Kusek GK, Yang M, Phoenix JL, Bolivar VJ, Crawley JN (2008) Autism-like behavioral phenotypes in BTBR $\mathrm{T}+\mathrm{tf} / \mathrm{J}$ mice. Genes Brain Behav 7(2):152-163

McNamara RK, Logue A, Stanford K, Xu M, Zhang J, Richtand NM (2006) Dose-response analysis of locomotor activity and stereotypy in dopamine D3 receptor mutant mice following acute amphetamine. Synapse 60(5):399-405

Meyer U, Feldon J, Schedlowski M, Yee BK (2005) Towards an immuno-precipitated neurodevelopmental animal model of schizophrenia. Neurosci Biobehav Rev 29(6):913-947

Meyza KZ, Blanchard DC, Pearson BL, Pobbe RL, Blanchard RJ (2012) Fractone-associated $\mathrm{N}$-sulfated heparan sulfate shows reduced quantity in BTBR $\mathrm{T}+\mathrm{tf} / \mathrm{J}$ mice: a strong model of autism. Behav Brain Res 228(2):247-253

Moey C, Hinze SJ, Brueton L, Morton J, McMullan DJ, Kamien B, Barnett CP, Brunetti-Pierri N, Nicholl J, Gecz J, Shoubridge C (2015) Xp11.2 microduplications including IQSEC2, TSPYL2 and $\mathrm{KDM} 5 \mathrm{C}$ genes in patients with neurodevelopmental disorders. Eur J Hum Genet. doi:10.1038/ejhg.2015.123

Mosher LJ, Frau R, Pardu A, Pes R, Devoto P, Bortolato M (2015) Selective activation of $\mathrm{D}$ dopamine receptors impairs sensorimotor gating in Long-Evans rats. Br J Pharmacol. doi:10.1111/bph.13343

Moy SS, Nadler JJ, Perez A, Barbaro RP, Johns JM, Magnuson TR, Piven J, Crawley JN (2004) Sociability and preference for social novelty in five inbred strains: an approach to assess autistic-like behavior in mice. Genes Brain Behav 3(5):287-302

O'Daly OG, Joyce D, Stephan KE, Murray RM, Shergill SS (2011) Functional magnetic resonance imaging investigation of the amphetamine sensitization model of schizophrenia in healthy male volunteers. Arch Gen Psychiatry 68(6):545-554

Ornitz EM, Hanna GL, de Traversay J (1992) Prestimulation-induced startle modulation in attention-deficit hyperactivity disorder and nocturnal enuresis. Psychophysiology 29(4):437-451

Ornitz EM, Russell AT, Hanna GL, Gabikian P, Gehricke JG, Song D, Guthrie D (1999) Prepulse inhibition of startle and the neurobiology of primary nocturnal enuresis. Biol Psychiatry 45(11):1455-1466

Ozbun LL, You L, Kiang S, Angdisen J, Martinez A, Jakowlew SB (2001) Identification of differentially expressed nucleolar TGF-beta1 target (DENTT) in human lung cancer cells that is a new member of the TSPY/SET/NAP-1 superfamily. Genomics 73(2):179-193

Pinkham AE, Penn DL, Perkins DO, Lieberman J (2003) Implications for the neural basis of social cognition for the study of schizophrenia. Am J Psychiatry 160(5):815-824

Piontkewitz Y, Arad M, Weiner I (2011) Risperidone administered during asymptomatic period of adolescence prevents the emergence of brain structural pathology and behavioral abnormalities in an animal model of schizophrenia. Schizophr Bull 37(6):1257-1269

Piven J, Arndt S, Bailey J, Havercamp S, Andreasen NC, Palmer P (1995) An MRI study of brain size in autism. Am J Psychiatry 152(8):1145-1149

Roussos P, Giakoumaki SG, Zouraraki C, Fullard JF, Karagiorga VE, Tsapakis EM, Petraki Z, Siever LJ, Lencz T, Malhotra A, Spanaki C, Bitsios P (2015) The relationship of common risk variants and polygenic risk for schizophrenia to sensorimotor gating. Biol Psychiatry. doi:10.1016/j.biopsych.2015.06.019

Russell AJ, Mataix-Cols D, Anson M, Murphy DG (2005) Obsessions and compulsions in Asperger syndrome and high-functioning autism. Br J Psychiatry 186:525-528

Silverman JL, Yang M, Lord C, Crawley JN (2010) Behavioural phenotyping assays for mouse models of autism. Nat Rev Neurosci 11(7):490-502
Spooren W, Mombereau C, Maco M, Gill R, Kemp JA, Ozmen L, Nakanishi S, Higgins GA (2004) Pharmacological and genetic evidence indicates that combined inhibition of NR2A and NR2B subunit containing NMDA receptors is required to disrupt prepulse inhibition. Psychopharmacology 175(1):99-105

Strakowski SM, Sax KW, Setters MJ, Stanton SP, Keck PE Jr (1997) Lack of enhanced response to repeated d-amphetamine challenge in first-episode psychosis: implications for a sensitization model of psychosis in humans. Biol Psychiatry 42(9):749-755

Sun G, Yuen Chan S, Yuan Y, Wang Chan K, Qiu G, Sun K, Ping Leung M (2002) Isolation of differentially expressed genes in human heart tissues. Biochim Biophys Acta 1588(3):241-246

Talledo JA, Sutherland Owens AN, Schortinghuis T, Swerdlow NR (2009) Amphetamine effects on startle gating in normal women and female rats. Psychopharmacology 204(1):165-175

Tao KP, Fong SW, Lu Z, Ching YP, Chan KW, Chan SY (2011) TSPYL2 is important for G1 checkpoint maintenance upon DNA damage. PLoS One 6(6):e21602

Tarpey PS, Smith R, Pleasance E, Whibley A, Edkins S, Hardy C, O'Meara S, Latimer C, Dicks E, Menzies A, Stephens P, Blow M, Greenman C, Xue Y, Tyler-Smith C, Thompson D, Gray K, Andrews J, Barthorpe S, Buck G, Cole J, Dunmore R, Jones D, Maddison M, Mironenko T, Turner R, Turrell K, Varian J, West S, Widaa S, Wray P, Teague J, Butler A, Jenkinson A, Jia M, Richardson D, Shepherd R, Wooster R, Tejada MI, Martinez F, Carvill G, Goliath R, de Brouwer AP, van Bokhoven H, Van Esch H, Chelly J, Raynaud M, Ropers HH, Abidi FE, Srivastava AK, Cox J, Luo Y, Mallya U, Moon J, Parnau J, Mohammed S, Tolmie JL, Shoubridge C, Corbett M, Gardner A, Haan E, Rujirabanjerd S, Shaw M, Vandeleur L, Fullston T, Easton DF, Boyle J, Partington M, Hackett A, Field M, Skinner C, Stevenson RE, Bobrow M, Turner G, Schwartz CE, Gecz J, Raymond FL, Futreal PA, Stratton MR (2009) A systematic, large-scale resequencing screen of X-chromosome coding exons in mental retardation. Nat Genet 41(5):535-543

Thomas A, Burant A, Bui N, Graham D, Yuva-Paylor LA, Paylor R (2009) Marble burying reflects a repetitive and perseverative behavior more than novelty-induced anxiety. Psychopharmacology 204(2):361-373

Tsang KH, Lai SK, Li Q, Yung WH, Liu H, Tao KP, Mak PHS, McAlonan G, Chan YS, Chan SY (2014) The nucleosome assembly protein TSPYL2 regulates the expression of NMDA receptor subunits GluN2A and GluN2B. Sci Rep 4:3654

Vidal CN, Nicolson R, Boire JY, Barra V, DeVito TJ, Hayashi KM, Geaga JA, Drost DJ, Williamson PC, Rajakumar N, Toga AW, Thompson PM (2008) Three-dimensional mapping of the lateral ventricles in autism. Psychiatry Res 163(2):106-115

Wan FJ, Geyer MA, Swerdlow NR (1995) Presynaptic dopamineglutamate interactions in the nucleus accumbens regulate sensorimotor gating. Psychopharmacology 120(4):433-441

Wang GS, Hong CJ, Yen TY, Huang HY, Ou Y, Huang TN, Jung WG, Kuo TY, Sheng M, Wang TF, Hsueh YP (2004) Transcriptional modification by a CASK-interacting nucleosome assembly protein. Neuron 42(1):113-128

Zhang L, Shirayama Y, Iyo M, Hashimoto K (2007) Minocycline attenuates hyperlocomotion and prepulse inhibition deficits in mice after administration of the NMDA receptor antagonist dizocilpine. Neuropsychopharmacology 32(9):2004-2010

Zhang X, Li Q, Wong N, Zhang M, Wang W, Bu B, McAlonan GM (2015) Behaviour and prefrontal protein differences in C57BL/ $6 \mathrm{~N}$ and $129 \mathrm{X} 1 / \mathrm{SvJ}$ mice. Brain Res Bull 116:16-24 